\title{
6. National Energy Market Integration
}

A study of energy price convergence in China

Oing King Guo, Chi Keung Marco Lau, Kunwang Li and Ligang Song

\section{Introduction}

Energy price convergence is one of the leading indicators for understanding market liberalisation and integration. The first contribution to the literature on the success of Chinese market reform and market integration is Young (2000). The author uses simple trends in the regional variance of prices to quantify market liberalisation and integration. Fan and Wei (2006), however, cast doubt on Young's controversial finding that China's internal markets became less rather than more integrated during the reform period. Fan and Wei used a nonlinear panel unit root test and found 'strong evidence of price convergence and hence market integration in China. Such a finding is in favour of the view that China's transition to a market economy has been quite successful during the last two decades' (2006: 692).

Following the method of Fan and Wei (2006), Ma et al. (2009) use a linear panel unit root test and focus on the energy market; they found evidence that energy prices are mostly converging to the national average price. They further suggested that if policymakers actually want to control energy markets in the future, they need to devise new ways to intervene in the energy sector, otherwise the reforms they have introduced have clearly led to a more market-oriented energy sector' (Ma et al. 2009: 4848). The work of Fan and Wei (2006) and Ma et al. (2009) links price convergence to market liberalisation and internal market integration by adopting the 'law of one price' (LOP) and arbitrage behaviour.

The LOP implies that identical goods sold in different locations tend to converge to the same price if markets for those goods are fully developed and transport costs are controlled for, indicating purchasing power parity (PPP) in the international context. In the 1980s, a vast literature studied price convergence and the speed of adjustment for international markets, using unit root and cointegration techniques. In the 1990s, researchers shifted their focus and interest from international to intra-national studies of price convergence, in part 
because the latter are subject to less restrictive assumptions for $\mathrm{PPP}^{1}$ (Parsley and Wei 1996). Many intra-country studies have examined whether the LOP holds (for example, Fan and Wei 2006; Lan and Sylwester 2010).

It is the conventional view that arbitrage opportunity among regions exists such that for the same good, trade will take place for agents to make a profit. In the long run, prices in different regions should converge to a single level, assuming zero or negligible transaction costs - say, transportation costs. In the literature, only nonlinear unit root tests can release the non-zero transaction cost assumption. Some recent examples of convergence studies that link convergence phenomena and policy reform, market integration and marketisation include Lau et al. (2015) for military expenditure convergence for the world; Lau et al. (2014) for healthcare expenditure in the European Union; Bilgin et al. (2010) for rental price convergence in Turkey; Akhmedjonov et al. (2013) for income convergence in Russia; and Suvankulov et al. (2012) for gasoline price convergence in Canada.

Empirical literature devoted to price convergence of energy markets in China remains limited (Ma et al. 2010). Fan and Wei (2006) are the first to investigate internal market integration in China using the unit root test. Their empirical results provide evidence for the proposition that gradualist reform has been quite successful in effecting the transformation from a planned to a marketoriented economy. ${ }^{2}$

Since a free and competitive market with a price mechanism underlies efficient resource allocation, this is of central concern for a transitional and per capita resource-poor economy such as China. The price dynamics of China's energy sector in particular are critical to market integration, not only because the energy market has been closely associated with manufacturing activities and environmental issues, but also because these are exposed to international energy price fluctuations. Moreover, China has 30 provinces and provinciallevel municipalities, and each of these is unique in terms of demographic structure, geography and level of development. This also suggests that these characteristics may affect the market integration for goods and energy products, and vice versa. ${ }^{3}$

1 For example, the theory assumes that the transaction for mobile goods takes place converging towards PPP only under competitive market conditions for both countries without incurring transportation costs, barriers to trade and other transaction costs. It can be argued that these conditions are more valid in intra-national than international settings.

2 In this chapter, we denote the success of this transformation as 'marketisation'.

3 Fan and Wei (2006) found evidence of a higher degree of market integration for major cities in the coastal region for commodities including raw industrial materials, processed industrial materials, durable goods and vehicles, and services. Moreover, we cannot exclude the possibility that a higher degree of market integration (that is, allocative efficiency) affects the development level. 
The purpose of this chapter is to examine price convergence among key energy products, such as gasoline, diesel, coal and gas across different regions in China over the sample period. This exercise helps shed light on the marketisation process in China, which has been being introduced incrementally for some three decades now. In addition, understanding whether domestic energy markets are more integrated across different regions can retrospectively and prospectively inform the reform process in China. Where a lack of evidence of price convergence is found for key energy products between regions in China, this could imply that Chinese domestic markets are not closely integrated, and that central and local governments should persist in extending relevant policy designs and implementation. Finally, a clear understanding of the price dynamic is important for designing economic policies, such as setting the level of the minimum wage in different locations across China.

China's industrialisation massively increased demand for energy. By 2005, and immediately following the annual growth of 3 per cent in energy intensity of gross domestic product (GDP) (the ratio of energy consumption per unit of GDP) during 2002-05 (Zhou et al. 2010), the government reached a consensus that rapid increases in energy demand were unsustainable. A decision was taken to reduce the energy intensity of GDP, via improved energy efficiency, and this in turn would be driven in part by marketisation of energy prices. With the energy intensity of China's GDP in 2007 being almost three times higher than the world average (Ma et al. 2009), ${ }^{4}$ a series of goals was set to improve China's energy efficiency levels.

Table 6.1 Recent key energy policies supporting China's 20 per cent reduction goal

\begin{tabular}{|l|l|l|}
\hline Energy policies & Date effective & Responsible agency \\
\hline Fuel consumption limits for passenger cars & 2004 & 2005 \\
\hline Medium and long-term plan for energy conservation & $\begin{array}{l}\text { National Development and } \\
\text { Reform Commission (NDRC) }\end{array}$ \\
\hline Renewable Energy Law & 2005 & $\begin{array}{l}\text { NDRC and Ministry of } \\
\text { Finance (MoF) }\end{array}$ \\
\hline Government procurement program & 2005 & $\begin{array}{l}\text { Ministry of Construction } \\
\text { (MoC) }\end{array}$ \\
\hline $\begin{array}{l}\text { National energy efficient design standard for public } \\
\text { buildings }\end{array}$ & 2005 & NDRC \\
\hline Eleventh Five-Year Plan & 2006 & State Council \\
\hline $\begin{array}{l}\text { State Council decision on strengthening energy } \\
\text { conservation }\end{array}$ & 2006 & MoF \\
\hline $\begin{array}{l}\text { Reduced export tax rebates for many low value- } \\
\text { added but high energy-consuming products }\end{array}$ & 2006 & NDRC \\
\hline Top 1,000 Energy-Consuming Enterprise program & 2006 & \\
\hline
\end{tabular}

4 For China, the energy intensity was 0.91 tonnes of oil equivalent per US\$1,000 GDP (at 2000 prices) in comparison with 0.32 for the world average and 0.19 in Organisation for Economic Cooperation and Development (OECD) countries as reported by NBS (2007). 
China's Domestic Transformation in a Global Context

\begin{tabular}{|c|c|c|}
\hline Energy policies & Date effective & Responsible agency \\
\hline 'Green Purchasing' program & 2006 & $\begin{array}{l}\text { Ministry of Environment } \\
\text { Protection (MEP) and MoF }\end{array}$ \\
\hline Revision of Energy Conservation Law & 2007 & $\begin{array}{l}\text { National People's Congress } \\
\text { and NDRC }\end{array}$ \\
\hline $\begin{array}{l}\text { Allocation of funding on energy efficiency and } \\
\text { pollution abatement }\end{array}$ & 2007 & MoF and NDRC \\
\hline China energy technology policy outline & 2007 & $\begin{array}{l}\text { NDRC and the Ministry of } \\
\text { Science and Technology }\end{array}$ \\
\hline Government Procurement program & 2007 & NDRC and MoF \\
\hline National Phase III Vehicle Emission Standards & 2007 & \\
\hline $\begin{array}{l}\text { Interim administrative method for incentive funds for } \\
\text { heating and metering and energy efficiency retrofit } \\
\text { for existing residential buildings in China's northern } \\
\text { heating area }\end{array}$ & 2007 & MoF \\
\hline $\begin{array}{l}\text { Law on Corporate Income Tax (preferential tax } \\
\text { treatment for investment in energy-saving and } \\
\text { environmentally friendly projects and equipment) }\end{array}$ & 2008 & NDRC \\
\hline $\begin{array}{l}\text { Allocation of funding on energy efficiency and } \\
\text { pollution abatement }\end{array}$ & 2008 & MoF and NDRC \\
\hline Appliance standards and labelling & Various years & $\begin{array}{l}\text { General Administration } \\
\text { of Quality Supervision, } \\
\text { Inspection and Quarantine }\end{array}$ \\
\hline
\end{tabular}

Source: Zhou et al. (2010).

The reforms instigated in 2005 were both broad and deep. Table 6.1 outlines a selection of the key policies, providing background to the direction of those reforms and also to the governance of that reform element. Energy-related quantitative goals agreed in November 2005 included a 20 per cent reduction of energy intensity of GDP by 2010, part of which could be achieved by closing small plants and phasing out outdated capacity in high-consumption industry sectors. ${ }^{5}$ Subsequent measures were designed and implemented, including laws, regulations and tax incentives to increase energy efficiency (Table 6.1) (Zhou et al. 2010). For such market-oriented measures to work effectively, parallel energy market reforms are required to allow energy product prices to move towards market-determined prices - a process that would also reduce differences in energy prices across different regions. This study explores that process of energy price convergence within China.

A sample period spanning 2006-12 is chosen for the study. This period begins one year after the initial set of energy pricing reforms began, in 2005, allowing for a time lag in policy outcomes. The time structure also implicitly allows for study of the impact of the energy pricing mechanism on energy efficiency (Ma et al. 2009) in testing the spatial convergence of energy prices during the

5 The 10 industries of iron, steel, cement, coal-fired power, coking, ferrous metal, glass, paper, ethanol and coal production. 
key period in which energy reform policies applied, and especially the target of 20 per cent energy efficiency improvement by 2012 as set in 2005 . The rationale for analysing the energy price convergence trend between Chinese regions is that segmentation of energy markets across the country is likely to undermine energy-related reforms.

Further, to date there has been insufficient attention in the literature to China's energy markets. This means there is insufficient evidence on energy price convergence in China and, accordingly, little is known about the efficiency of reforms. Ma et al. (2009), for example, studied the spot price for four energy products - coal, electricity, gasoline and diesel - but only covering 35 provincial (or autonomous region and municipality) capital cities across one decade from 1995. This study utilises a richer and updated dataset, and studies the energy market landscape following recent reforms.

\section{Data}

Data used are collected from the Price Supervision Centre of the National Development and Reform Commission (NDRC). These data cover 20 types of energy products from the five key energy product categories: coal, gasoline, diesel, electricity and gas. Moreover, these data were collected at 10-day intervals, on the 5th, 15th and 25th of each month, from 2006 to 2012. The advantage of high-frequency data is that they contain more information regarding arbitrage opportunities and convergence speed (Bachmeier and Griffin 2006; Ma et al. 2009; Taylor 2001). Setting the sample period to coincide with the key energy market reform era also provides scope to examine the degree of regional energy price convergence during the implementation phase of important energy policies in China. Detailed descriptions of data and the number of cities and provinces involved in each energy product are provided in the Appendix for this chapter.

Finally, the sample period coincides with the large fiscal stimulus package implemented by China's government in response to the global financial crisis (GFC). This sought to boost demand, impacting both energy prices and energy efficiency. If substantial variation in energy prices between regions in China in the post-crisis period is uncovered, this could be related to the large scale of the fiscal stimulus package. In this case, the stimulus may have been effective in boosting domestic demand, but it could also have served to undermine energy market integration in the process. The design of this study is expected to reveal useful information on energy markets in China, and also on the wider issues within that market of spatial convergence or divergence over time and between locations. 


\section{Preliminary analysis: Historical average energy product price trend}

\section{Gasoline and diesel}

We first individually examine the pattern of price change over time for each energy product. Figure 6.1 shows the trend in average price - the mean of spot price at time ' $\mathrm{t}$ ' across all regions - for each product. We observe that after 2009 the average price of gasoline products was more volatile. From 2009 to 2012, that price also rose far more sharply than from 2006 to 2008. Specifically, from 2009 to 2012, the average price climbed by RMB4,000 per tonne-double the rate of the earlier period, 2006-08.

Price movement of diesel products is similar to that of gasoline products. This could relate to the oil price reform launched in 2009, under which domestic fuel prices were adjusted over a 22-day working period in response to a 4 per cent increase in Brent, Dubai and Cinta crude oil prices. A policy of explicit market response was linked to participants being free to set prices below the maximum retail price regulated by the government. This could also have contributed to higher price volatility after 2009. Finally, in 2013 the market was liberalised further and the prices of oil products were allowed to be adjusted every 10 working days, instead of every 22 days, to better reflect global oil price movement.
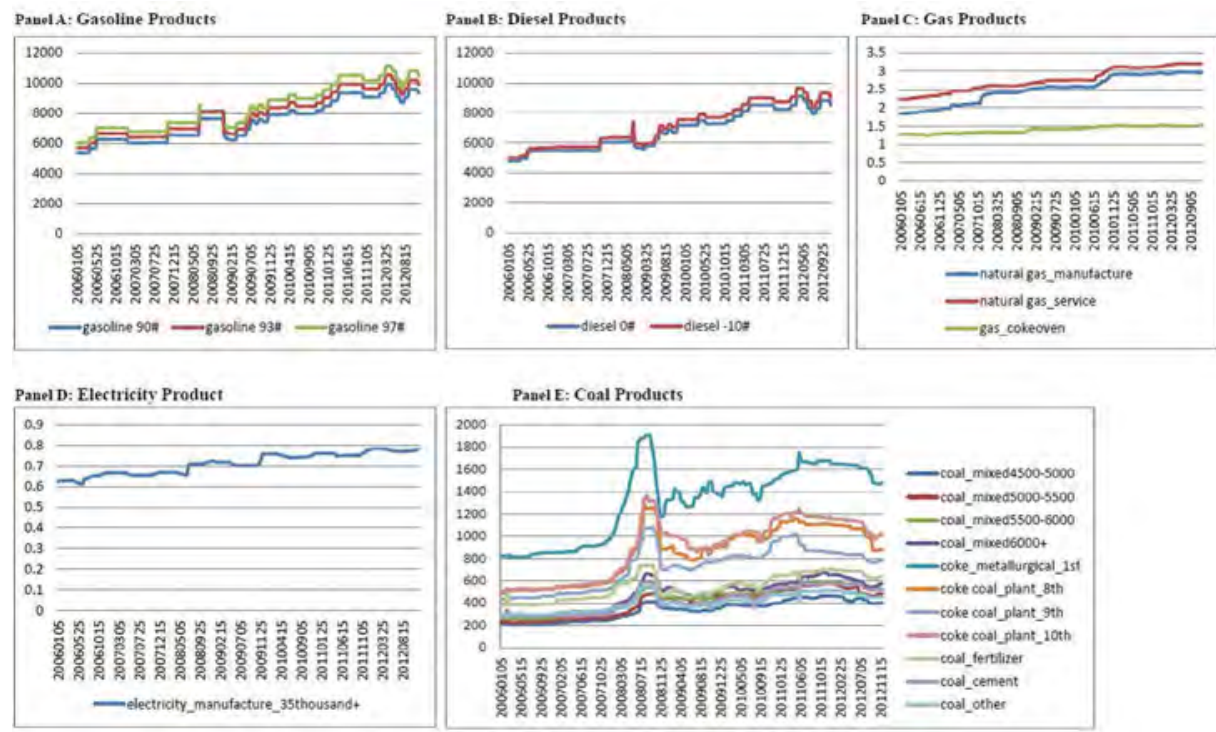

Figure 6.1 Historical average prices of energy products in China

Source: Plotted using the survey data. 


\section{Gas, electricity and coal}

There is less movement in the gas price than in the prices of gasoline and diesel. Price changes that did take place in 2007 and 2010 are probably attributable to reform policies, including the 2007 price adjustment policy and energy intensity reduction reforms that were adopted in 2010 .

Coal product prices show a similar pattern of gradual increase before 2007, followed by a dramatic increase, and finally a substantial drop during the GFC. Since the beginning of 2009, all coal product prices remained steady, until the second half of 2011, when prices tended to decrease gradually.

\section{Preliminary analysis: Comparison of energy price trend}

Table 6.2 presents the average spot prices and their changes for 20 energy products. The price of coal shows higher volatility than other energy products. For many coal products, the price in 2012 was double that in 2006 - the result of an annual growth rate for coal products that was mostly above 11 per cent across the sample period. For diesel products, the price in 2012 was about 67 per cent more than the price in 2006. For gasoline products, the price in 2012 was 57 per cent more than the price in 2006, reflecting an annual average growth rate of 7.8 per cent. ${ }^{6}$ Finally, compared with coal, gasoline and diesel, the prices of gas and electricity rose less rapidly. Gas increased by 40 per cent and electricity increased by an annual rate of 3.4 per cent, or 22 per cent over the sample period.

In addition to such price variation between different energy categories, price variation within energy product category groups is phenomenal. Coal and gas in particular have many subcategory products, and these have different growth rates. In the case of coal, the 2006-12 change in the price of 'coal_mixed5000$5500^{\prime 7}$ was a striking 1,275 per cent, while that for 'coal fertiliser' was only 35 per cent. Similar observations are found within gas product prices; however, this is not the case for gasoline or diesel products. The price changes of all gasoline and diesel subcategories are the same. This could imply that the markets for gasoline, diesel and electricity are subjected to greater regulation than the markets for coal and gas.

6 By coincidence, China's growth trajectory depending on political calibrations is also 7.8 per cent GDP growth.

7 '5000-5500' refers to the calorific value; this category belongs to the 'sub-bituminous' rank and the moisture content is $20-40$ per cent. For more information, see: www.coalmarketinginfo.com/coal-basics. 


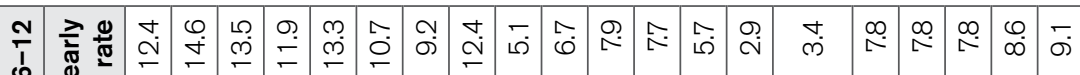

సิ ำ

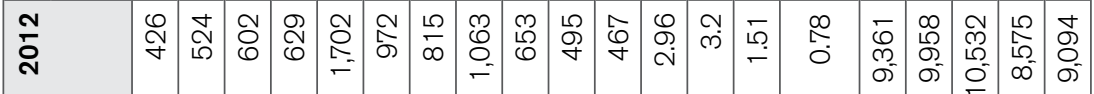

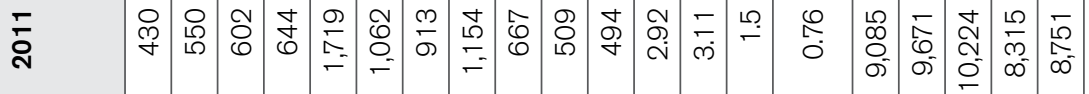

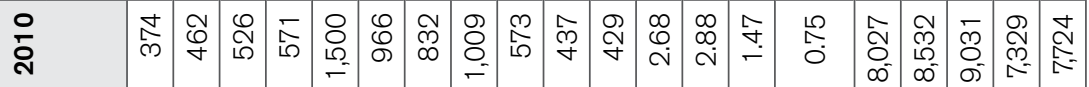

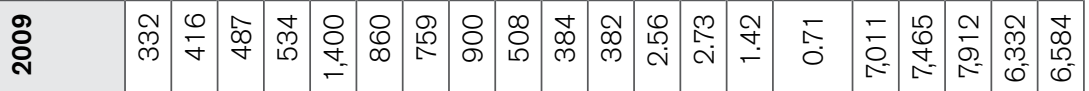

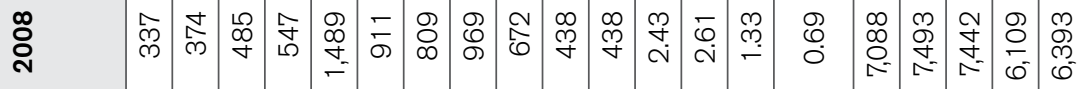

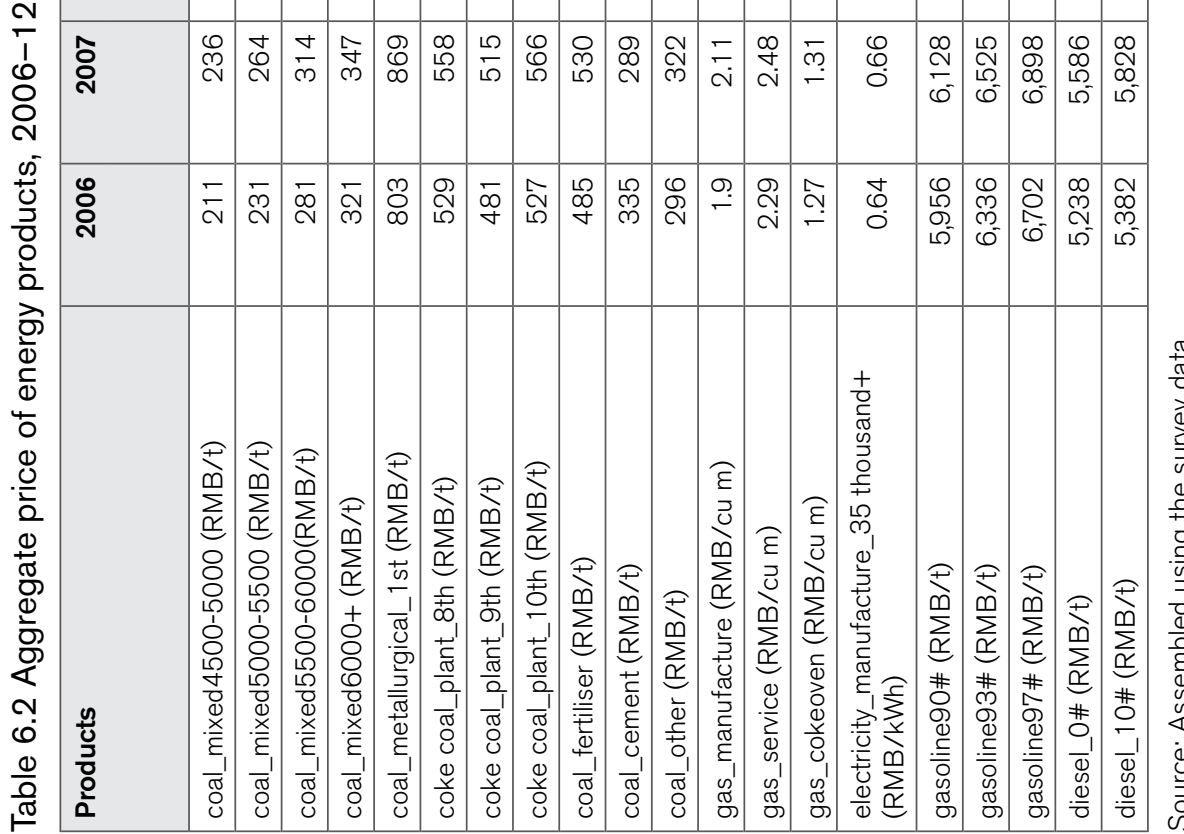




\section{Preliminary analysis: Trend for coefficient of variation}

The coefficient of variation is defined as the standard deviation over the mean price over each region at time ' $t$ ', and shows the extent of price variability across regions. Figure 6.2 shows coefficients of variation for energy products in China, which we explored next.

\section{Gasoline}

Panel B of Figure 6.2 shows the trend for the coefficient of variation attached to gasoline products. First, we observe more frequent regional variation after 2009, which may be attributable to market reform policies launched in 2009 that allowed greater arbitrage activity in the gasoline products market. Second, after mid-2009, the coefficient was not only subject to more variation, but also demonstrated a consistent pattern of increase.

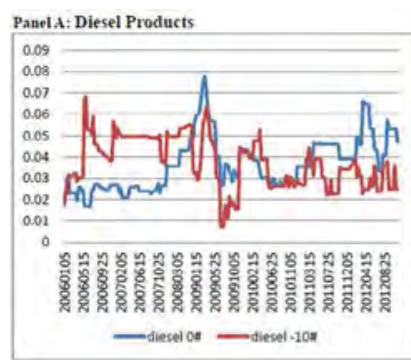

Panel D; Electricity Product

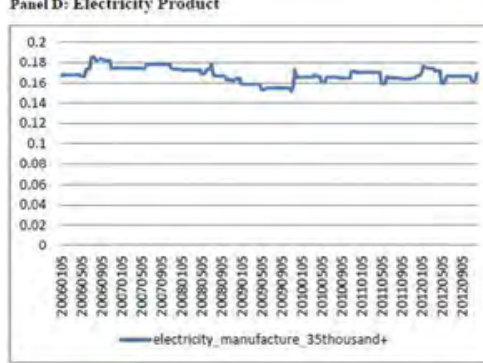

Panel B: Gasoline Products

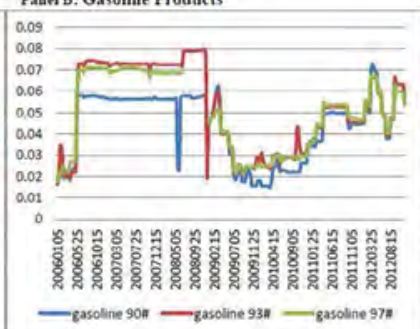

Panel C: Gas Products

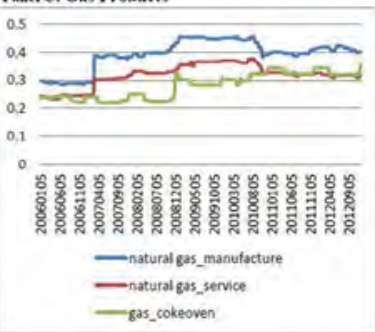

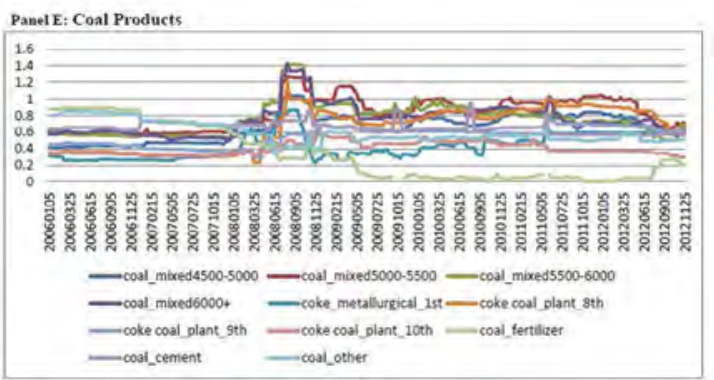

Figure 6.2 Coefficient of variation for energy products in China

Source: Plotted using the survey data. 


\section{Diesel}

For product line 'diesel 10\#', the coefficient of variation stabilised after 2009. As in the case of gasoline products, this could be the result of oil price reforms that were launched in 2009. There were differences, however, between the variation of gasoline products and that of diesel products. The coefficients of variation for diesel and gasoline were both about 0.03 in 2009. For diesel products, price divergence across major cities is not obvious; however, the price variation of gasoline products started to climb after 2009, indicating that the price stabilisation program is not very efficient.

\section{Gas and electricity}

For both service gas and manufacturing gas, the coefficient of variation jumped in 2007, and continued to rise slowly until the end of 2010, when it began to fall. These turning points in 2007 and 2010 could be attributed to government price adjustment in 2007 and broader price reforms in 2010. The coefficient of variation attached to electricity decreased slowly from 2006 to 2010, and remained relatively stable thereafter.

\section{Coal}

Several observations can be made about the coefficient of the variation trend attached to coal products. First, the coefficient had more frequent ups and downs after 2008 than before 2008; also from 2008, the level of the coefficient was higher than before 2008. Second, the gap in the coefficient of variation between different coal products became larger after 2008. These observations could be linked to reforms in 2008 that deregulated the market for coal by allowing prices to better reflect supply and demand. Third, it is interesting to see the coefficient for fertiliser coal hitting zero from $2009 .{ }^{8}$ Fourth, we note that prices for coal, gasoline and diesel all became more volatile after the reform period, implying that market reforms in the energy sector in general have produced more frequent arbitrage activities.

Finally, we observe that the coefficient of variation attached to coal product prices changed substantially after the GFC. This could reflect outcomes attached to government fiscal stimulus policy that sought to boost crisis-affected demand.

8 For details, see: www.fertmarket.com/newsabout.aspx?id=37. The reason for this trend is not clear; however, fertiliser coal is the raw material for most of China's nitrogen fertiliser, and nitrogen fertiliser received subsidies of about US\$7.46 billion during 2008-09 (Heffer and Olegario 2010). 
In sum, these preliminary observations provide evidence of price change within energy product markets in China between 2006 and 2012. In the next section, we test to see if the direction of these energy price changes is towards convergence or divergence across different regions in China and over the sample period.

\section{Testing for energy price convergence: A series- specific nonlinear panel unit root test}

We use a nonlinear panel unit root test that is series specific (see Breuer et al. 2002; Kapetanios et al. 2003; Lau et al. 2012; Wu and Lee 2009). This series-specific nonlinear panel unit root test model (hereinafter NNSS) has several advantages over the conventional panel unit root tests. The NNSS is advantageous in testing for stationarity for each city, while the model itself accounts for nonlinearity and contemporaneous correlation among cross-section series - statistical features that are widely identified in financial and economic datasets.

In the case of our dataset, cross-sectional dependence is a distinctive feature. Cities are heterogeneous - that is, in the culture of doing business, local governmental policies, languages, consumer preferences, and market structure and international exposure - but to some extent they are affected by common factors, such as using the same currency, the same time zone and the same written language. External shocks to the foreign exchange rate and the international oil price, for example, will in turn uniquely influence energy prices in different cities.

The most significant common factors between Chinese cities - but which differ from other major economies - are China's unique political institutions. China operates with a unique intra-provincial political system known as the Regionally Decentralised Authoritarian System (Xu 2011). Most influentially, this serves to link regional economic performance to the career promotion of officials - that is, regional competition provides incentives to sub-national officials to initiate and implement market-oriented reforms ( $\mathrm{Xu}$ 2011). Under this institutional arrangement, sub-national officials tend to accept and implement (rather than resist and initiate) policies formulated by the central government. These policies work as common factors that influence every city to a certain degree. When conducting research in this political institutional setting, the issue of crosssectional dependence should not be ignored.

We use the seemingly unrelated regression (SUR) method in this study, with $\mathrm{N}$ cities and $\mathrm{T}$ time periods. The following simultaneous equations form the nonlinear SUR model, as in Equation 6.1. 


\section{Equation 6.1}

$$
\begin{gathered}
\Delta y_{1, t}=\delta_{1} y_{1, t-1}^{3}+\sum_{j=1}^{\rho_{1}} \eta_{1, j} \Delta y_{1, t-j}+\varepsilon_{1, t} \\
\Delta y_{2, t}=\delta_{2} y_{2, t-1}^{3}+\sum_{\substack{\rho_{2} \\
\rho_{N-1}}}^{\rho_{2, j} \Delta y_{2, t-j}+\varepsilon_{2, t}} \\
\Delta y_{N-1, t}=\delta_{N-1} y_{N-1, t-1}^{3}+\sum_{j=1}^{\eta_{N-1, j} \Delta y_{N-1, t-j}+\varepsilon_{N-1, t}} \eta_{N, t}=\delta_{N} y_{N, t-1}^{3}+\sum_{j=1}^{\rho_{N}} \eta_{N, j} \Delta y_{N, t-j}+\varepsilon_{N, t}(1)
\end{gathered}
$$

In Equation 6.1, $\mathrm{t}=1,2, \ldots, \mathrm{T} ; p_{k, t}$ is the original price of a specific good for city $k$ at time $t ; y_{k, t}$ is the relative price defined as $y_{k, 1}=\ln \left(p_{k,} / \bar{p}_{t}\right)$; and $\overline{\mathrm{P}}_{\mathrm{t}}$ is the average price of a specific good for all cities at time $t . \Delta y_{k, t}=y_{k, t}-y_{k, t-1} \cdot \rho_{k}$ is thus the number of augmentations or lags for goods $k$. The null and alternative hypotheses to be tested are in Equation 6.2.

\section{Equation 6.2}

$\mathrm{H}_{0}^{k}: \delta_{k}=0 ; \mathrm{H}_{1}^{k}: \delta_{k}<0 \quad \forall k=1,2, \ldots, N$

The critical values are generated using a bootstrapping method because of the non-standard distribution of the test statistics. ${ }^{9}$ Here we modify the Gauss code provided by $\mathrm{Wu}$ and Lee (2009), ${ }^{10}$ and for each series, $y_{k, t^{\prime}}$ report t-statistic (SURt $\mathrm{NL}_{\mathrm{NL}}^{\mathrm{k}}$ statistic) results and the critical values at 5 per cent and 10 per cent. If the t-statistic is less than the 5 per cent SURt $\mathrm{NL}_{\mathrm{N}}^{\mathrm{k}}$ critical value, the null hypothesis of having a unit root is rejected; results reported in Table 6.3 are based on the 10 per cent SURt ${ }_{\mathrm{NL}}^{k}$ significance level. ${ }^{11}$

The rejection of the unit root hypothesis, $\mathrm{H}_{0}^{k}$, implies that the time series of price differentials is stationary; if tests fail to reject the null hypothesis, the price differentials follow a random walk. This means we can proceed to calculate the price differentials. To do this, we use the group average price (the mean of all the regions concerned for each product) as the benchmark. Hypothesis tests

9 A bootstrap-after-bootstrap method (Berkowitz and Kilian 2000) is applied to obtain the effective empirical sizes of bootstrap tests given the nominal size of 5 per cent.

10 We thank Jyh-Lin Wu for making the Gauss code available online. A sample code can be downloaded from Jyh-Lin Wu's homepage: econ.nsysu.edu.tw/files/11-1124-1326-1.php.

11 Detailed convergence test results for all energy products and regions are available on request. 
are conducted for a spot price panel dataset relating to each energy product. There are 20 energy products within five energy categories: gasoline, diesel, coal, gas and electricity.

This approach enables us to use time series analysis to test whether each region is converging to group average price. We can use some major cities as benchmarks - for example, we can examine whether prices in different cities converge with those in Shanghai or Guangzhou. We use a cross-sectional mean as the benchmark in our chapter because the coverage of reform policy is nationwide, and we intend to provide a more complete picture of the impact of reform policy on energy price convergence. More importantly, it was suggested in the literature that using a cross-sectional mean as the benchmark is preferable from an econometrics point of view for consistency (for details, see Akhmedjonov et al. 2013; Evans 1998; Lau 2010).

The study makes a unique contribution to the literature on energy price convergence as follows: first, the econometric model captures the characteristics of nonlinearity and cross-sectional dependence across regions; second, the study applies to a wider coverage of energy products than has previously been explored. On the latter, Fan and Wei (2006) tested only two energy products: gasoline and diesel. Ma et al. (2009) extended this to four energy products: gasoline, coal, diesel and electricity. This research covers 20 energy products from the five broad energy categories: gasoline, coal, diesel, electricity and gas. Third, this study covers the period after 2005, which is during the energy reform process. All previous studies were undertaken before 2005. Finally, earlier studies covered only 35 Chinese provinces, while ignoring the effects of energy prices in non-capital cities. Ours is not only the most recent such study undertaken, it is also the most comprehensive in terms of city coverage, and is unique in being able to capture the effects of ongoing energy reforms since 2006.

\section{Empirical results}

\section{Price convergence by energy category and product}

Table 6.3 summarises the share of cities showing evidence of nonlinear convergence to the average cross-regional energy price for all energy products. These suggest that, on average, 39.2 per cent of the sample cities exhibit nonlinear convergence and hence imply a level of energy price integration across regions in China. An earlier study concluded that more than 80 per cent 
of regions showed price convergence (Fan and Wei 2006). ${ }^{12}$ That study, however, only included gasoline and diesel products, and also covered only 36 major cities. The present study is more comprehensive along regional and product lines, and the results are thus more convincing that while energy market reforms are progressing, they are not yet effective enough to lead to more widespread convergence in energy prices.

A study by Ma et al. (2009), meanwhile, suggested that convergence applied to a lower share of cities: only 26 per cent. Unfortunately, their conclusion was based on a univariate augmented Dickey-Fuller (ADF) test. This is widely criticised for its lack of statistical power in rejecting the null hypothesis of a unit root. The empirical findings of this research - that 39.2 per cent of cities exhibit convergence - are more reliable as our testing method incorporates panel data, nonlinearity and cross-sectional dependence.

Table 6.3 Percentage of nonlinear convergence by product type

\begin{tabular}{|l|l|l|l|l|l|}
\hline All & Coal & Diesel & Electricity & Gas & Gasoline \\
\hline $39.2 \%$ & $28.3 \%$ & $67.7 \%$ & $11.1 \%$ & $26.0 \%$ & $44.8 \%$ \\
\hline
\end{tabular}

Source: Authors' own calculations.

Table 6.4 presents the results by significant region by the five category types. The results show that the price of diesel is converging most, specifically across 67.7 per cent of regions sampled. The remaining products by order of degree of convergence are gasoline, coal, gas and electricity - a result that merges perfectly with Ma et al. (2009).

For the above results, we conclude that coal and gas markets are less integrated than those of diesel and gasoline, leaving the electricity market as the least integrated of the five categories. According to these results, we cannot conclude that China's energy markets are well integrated. In contrast, these results highlight the limited convergence achieved by the energy reform agenda.

12 The authors claimed that 31 of 35 cities ( 88.6 per cent) were convergent for gasoline and 30 of 34 cities (88.2 per cent) for diesel, which suggests some degree of market integration for gasoline and diesel. Meanwhile, the study of Ma et al. (2009) and our current research suggest that the diesel market is much more integrated than the gasoline market. 


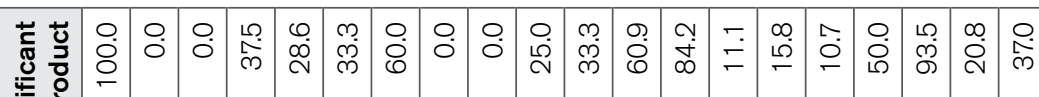

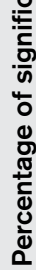

䒕

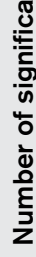

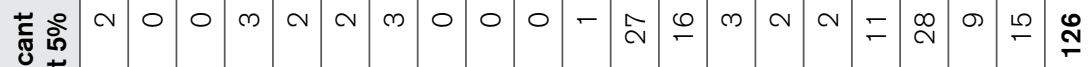

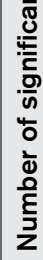

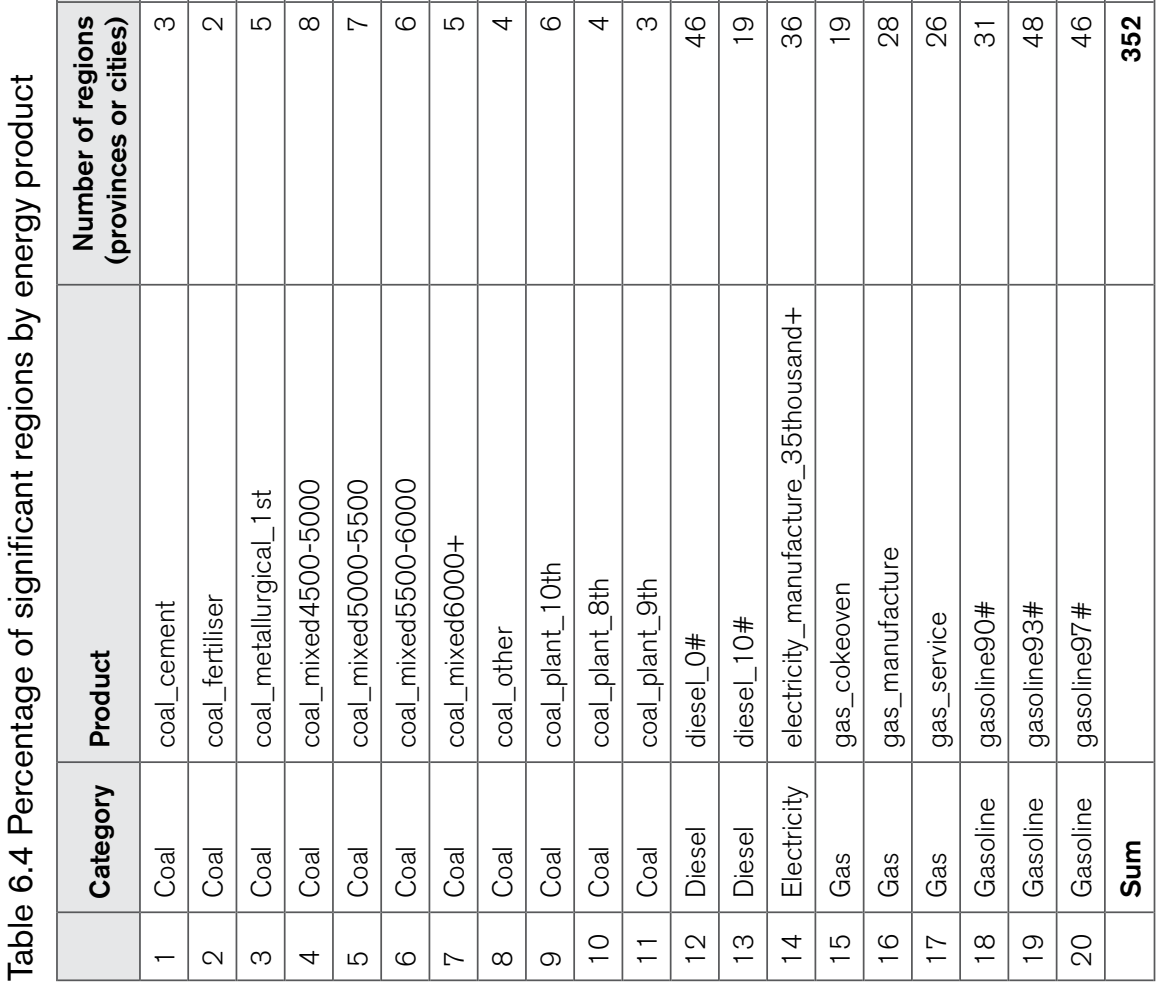


An additional contribution of this study is that we provide detailed information on the percentage of converging major cities for each subcategory of energy product. These results are presented in Table 6.4, several observations from which are worth highlighting. First, the prices of some products demonstrate a far higher level of regional convergence than for other products. At the extreme, price convergence is taking place among 93.5 per cent of cities for 'gasoline90\#', where that level of convergence is 0 per cent for 'coal_plant_10th'.

Second, the level of price convergence across products in the same energy category is different across each of the five energy categories. For example, within the gas category, 'gasoline93\#' and 'gasoline97\#' show a similar degree of regional price integration, but that level is much lower for 'gasoline90\#'. This could be because 'gasoline93\#' and 'gasoline97\#' display a similar degree of market integration, while 'gasoline90\#' exhibits the highest level of integration in this energy category.

Overall, our empirical findings suggest China's energy market is characterised by a low degree of domestic price integration. This implies that despite the implementation of a number of policies and reform mechanisms to encourage reform of the energy sector, the reform process is either incomplete or not comprehensive. It is also possible that significant transaction costs due to institutional factors, such as local protection, may contribute to this phenomenon of price divergence. ${ }^{13}$

Coal products, for example, dominate China's energy market. Coal met some 70 per cent of China's energy needs in 2009, and thanks to energy reforms this level of dependence is expected to fall to 62 per cent by 2035 (EIA 2012). In China's case, coalmine methane (CMM) recovery projects across the country have been playing an important role in coal-related power generation, town gas projects, as well as energy efficiency enhancement programs (US EPA 2012). CMM is, however, according to the US Environmental Protection Agency (US EPA), also associated with cross-regional integration barriers, including low-quality drained CMM, and explosive gas mixtures that make handling and transportation risky. In addition, there are inconsistent laws between provinces in terms of the level of methane concentration required for the use of CMM, which typically pivots about 30 per cent. Such factors reduce the ease with which energy reforms can stimulate cross-regional energy market integration in China.

13 For instance, the band of inaction could be widened by recent increases in salaries and transportation costs in China, especially in coastal regions. 


\section{Overall energy marketisation by province}

A final area of analysis of this chapter is to shed light on the literature on overall energy marketisation at the province level. Previous research examines the marketisation of certain energy categories or the general marketisation for a given province, as shown in column 7 in Table 6.5 (Fan et al. 2011). However, the criteria for assessing the general marketisation index published by Fan et al. (2011) is not transparent. There is limited evidence for energy marketisation at the province level. We therefore propose a new index for measuring marketisation within the energy industry for each province, as follows (Equation 6.3).

\section{Equation 6.3}

$M I=\frac{N T R}{N T T}$

In Equation 6.3, MI is the proposed index to proxy the degree of marketisation, as Fan and Wei (2006) also use the proportion of converging cities to quantify the effectiveness of transformation from a planned to a market-oriented economy for a specific commodity category in a particular city. NTR is the number of times convergence is detected (that is, the number of times the unit root test rejects the null of having a unit root test), and NTT is the number of appearances of cities in our study. Therefore MI (as shown in column C in Table 6.5) is the measure to proxy, and quantifies the effectiveness of market reform for the energy sector. ${ }^{14} \mathrm{~A}$ high index result thus implies a high level of marketisation in terms of a more market-oriented energy sector, as suggested by Ma et al. (2009). A high index ratio indicates that a province's energy market is characterised by a higher degree of marketisation in terms of a more marketoriented energy sector, and this is quantified, proxied by the province's average fuel price convergence level.

Table 6.5 Comparison of energy marketisation with general marketisation by province

\begin{tabular}{|l|l|r|r|r|r|r|r|}
\hline ID & Province & $\mathbf{A}^{\mathbf{a}}$ & $\mathbf{B}^{\mathbf{b}}$ & $\mathbf{C}^{\mathbf{c}}$ & $\mathbf{D}^{\mathbf{d}}$ & $\mathbf{E}^{\mathbf{e}}$ & $\mathbf{F}^{\mathbf{f}}$ \\
\hline 1 & Jilin & 13 & 10 & $77 \%$ & 1 & 18 & 17 \\
\hline 2 & Ginghai & 9 & 6 & $67 \%$ & 2 & 30 & 28 \\
\hline 3 & Guizhou & 17 & 11 & $65 \%$ & 3 & 26 & 23 \\
\hline 4 & Tianjin & 8 & 5 & $63 \%$ & 4 & 6 & 2 \\
\hline 5 & Hebei & 17 & 10 & $59 \%$ & 5 & 17 & 12 \\
\hline 6 & Liaoning & 16 & 9 & $56 \%$ & 6 & 9 & 3 \\
\hline
\end{tabular}

$14 \mathrm{Ma}$ et al. (2009) is the first study to use the unit root test methodology to examine the effect of policy reforms on energy price convergence, and they conclude that reforms have led to a more market-oriented energy sector in China (p. 4848). 


\begin{tabular}{|c|c|c|c|c|c|c|c|}
\hline ID & Province & $A^{a}$ & $\mathrm{~B}^{\mathrm{b}}$ & $\mathbf{C}^{c}$ & $D^{d}$ & $E^{e}$ & $\mathbf{F}$ \\
\hline 7 & Ningxia & 13 & 6 & $46 \%$ & 7 & 25 & 18 \\
\hline 8 & Hunan & 11 & 5 & $45 \%$ & 8 & 16 & 8 \\
\hline 9 & Chongqing & 7 & 3 & $43 \%$ & 9 & 10 & 1 \\
\hline 10 & Heilongjiang & 14 & 6 & $43 \%$ & 10 & 22 & 12 \\
\hline 11 & Henan & 7 & 3 & $43 \%$ & 11 & 12 & 1 \\
\hline 12 & Guangdong & 12 & 5 & $42 \%$ & 12 & 4 & -8 \\
\hline 13 & Shanghai & 8 & 3 & $38 \%$ & 13 & 2 & -11 \\
\hline 14 & Beijing & 6 & 2 & $33 \%$ & 14 & 5 & -9 \\
\hline 15 & Gansu & 6 & 2 & $33 \%$ & 15 & 29 & 14 \\
\hline 16 & Jiangxi & 9 & 3 & $33 \%$ & 16 & 15 & -1 \\
\hline 17 & Shandong & 33 & 11 & $33 \%$ & 17 & 8 & -9 \\
\hline 18 & Yunnan & 9 & 3 & $33 \%$ & 18 & 24 & 6 \\
\hline 19 & Shanxi & 16 & 5 & $31 \%$ & 19 & 23 & 4 \\
\hline 20 & Guangxi & 10 & 3 & $30 \%$ & 20 & 21 & 1 \\
\hline 21 & Jiangsu & 10 & 3 & $30 \%$ & 21 & 3 & -18 \\
\hline 22 & Sichuan & 10 & 3 & $30 \%$ & 22 & 13 & -9 \\
\hline 23 & Anhui & 11 & 3 & $27 \%$ & 23 & 11 & -12 \\
\hline 24 & Fujian & 8 & 2 & $25 \%$ & 24 & 7 & -17 \\
\hline 25 & Hainan & 4 & 1 & $25 \%$ & 25 & 19 & -6 \\
\hline 26 & Hubei & 12 & 3 & $25 \%$ & 26 & 14 & -12 \\
\hline 27 & Zhejiang & 16 & 4 & $25 \%$ & 27 & 1 & -26 \\
\hline 28 & Inner Mongolia & 22 & 5 & $23 \%$ & 28 & 20 & -8 \\
\hline 29 & Xinjiang & 5 & 1 & $20 \%$ & 29 & 28 & -1 \\
\hline 30 & Shaanxi & 12 & 2 & $17 \%$ & 30 & 27 & -3 \\
\hline 31 & Tibet & 1 & 0 & $0 \%$ & 31 & 31 & 0 \\
\hline
\end{tabular}

a Number of times cities appear.

b Number of times convergence is detected.

c Percentage (= column B, column A).

d Energy marketisation ranking using $\mathrm{MI}$ indicator.

e General marketisation index ranking, 2006-09 (Fan et al. 2011).

${ }^{f}$ Difference between ranking of energy marketisation and that of general marketisation (= column E - column D).

Notes: There are 31 provinces investigated. The Province column lists all the provinces. The data in column A indicate how many times they appear in all 352 hypothesis tests. The data in column B indicate how many times the corresponding hypothesis testing rejects the null hypothesis. Column $\mathrm{C}$ is generated as the ratio of column B over column A. Take Jilin Province as an example: it appears 13 times (see column $A$ ) in all 352 hypothesis tests among which 10 times found evidence of convergence (see column B). Column $\mathrm{C}$ is equal to 10,13 or 77 per cent. Column D ranks all provinces based on the data in column $\mathrm{C}$. Column $\mathrm{E}$ lists the ranking of the general marketisation based on the average marketisation index (2006-09) created by Fan et al. (2011). The lower the data are, the higher is the level of general marketisation. In column D, the datum for Zhejiang Province is 1 , which means the general market of Zhejiang is most developed during the period 2006-09. Column F is equal to column $E$ minus column $D$.

Source: Authors' own calculations. 
The overall indices ranks derived for each province are presented in column $\mathrm{C}$ of Table 6.5, and the ranking of general marketisation for each province is presented in column D. Jilin Province, in China's far north-east on the border with North Korea, and which experiences severe cold weather, is ranked first among China's provinces as the most market-oriented energy market. The reason for this observation is not clear, but it is interesting to note that the top 10 regions in terms of MI measures are all coastal provinces located north of the Yangtze River, ${ }^{15}$ and are classified as 'severely cold' heating zones. One reason for their successful implementation of price reform could be local government prioritisation as heating is required by law. Heating consumption in these regions accounts for about 7 per cent of aggregate gas demand compared with a national average of 2 per cent (Chen 2014). In contrast, Zhejiang Province, a coastal frontier south of Shanghai, was identified as the overall most integrated market using the published ranking of Fan et al. (2011).

Table 6.5 demonstrates that there is a lack of correlation between energy market convergence and the overall degree of commodity marketisation - the latter as identified by Fan et al. (2011), which fills the last column of Table 6.5. For example, one of China's most economically advanced provinces, Zhejiang, ranks first in terms of general marketisation, but 27th for energy sector marketisation. Similar results are identified for developed markets such as Shanghai, Jiangsu, Guangdong and Beijing. In contrast, provinces considered to have the highest level of market integration in the energy sector are mostly on the coast north of the Yangtse River, and are classified as 'severely cold' heating zones - such as Hebei, Tianjin, Liaoning, Jilin and Heilongjiang - where heating supply is required by law.

There may be several reasons for divergence between the marketisation process of the energy market and the general market across regions of China. First, our definition of 'marketisation' is different from that used by Fan et al. (2011): we use an econometrics test to define marketisation, while Fan et al.'s (2011) definition is comprehensive but ambiguous. Second, the source of a high degree of price convergence for less-developed provinces could be the intervention from the central government, rather than free-market arbitrage activities.

Energy products are among the most important inputs for economic development. Recent studies argue that local governments in China, especially those of more developed provinces, have incentives to control the price in the energy sector (Young 2000; Xu 2011). Further research is needed, however, to examine why these more developed regions are not exhibiting a high degree of price convergence, and hence a market-oriented energy sector. The lack of correlation between the results of our indices for energy and general market 
integration also calls for further research so as to better understand the role of energy markets in the general marketisation index ranking constructed by Fan et al. (2011). It could also be useful to calculate the same marketisation index of this study for single durable goods, non-durable goods and services in China, so as to have a better understanding of the marketisation process for different products across different cities and provinces.

\section{Conclusion}

Energy price convergence is one of the leading indicators for understanding market liberalisation and integration. Studies examining energy price convergence in China are limited in both quantity and findings. This study has added to the existing literature in several aspects. First, the dataset used here covers a previously unstudied period, despite its centrality within ongoing energy market reforms. Our dataset also offers higher data frequency and has wider regional coverage. Second, the methodology used in this study is more robust in capturing nonlinearity and cross-sectional dependence of the pricing process. Third, this research extends the range of energy products investigated to cover all the critical energy categories in the economy. It thus provides the most comprehensive analysis to date of pricing in China's energy sector.

We find little evidence of price convergence, as measured by convergence to the average price across provinces, between cities in Chinese energy markets from 2006-12. We take this to mean that China's domestic energy market is not well integrated across the country's cities. Examination of detailed energy categories finds few cities are moving towards price convergence for electricity, gas and coal. There is greater price convergence in gasoline and diesel, but these markets are far from perfectly integrated as far as the existence of a unified price would indicate.

The study also finds that the level of market integration varies between different products within the same broader energy type category. Similarly, the coefficients of variation in the price of some key energy products, such as gasoline, diesel, coal and gas, have changed substantially since the GFC. This could indicate that the combination of international volatility in prices and the large domestic fiscal stimulus package implemented by the Chinese Government in response to the GFC has caused variations in both energy prices and energy efficiency.

Moreover, by augmenting the general marketisation index ranking constructed by Fan et al. (2011), we find little association between energy marketisation and general marketisation across numerous provinces. That is, there are cases where provinces considered to be highly developed and integrated in general - such as Zhejiang, Shanghai, Jiangsu, Guangdong and Beijing - display an unexpectedly 
low level of energy market price integration. In contrast, provinces with a high level of energy market integration are mostly in areas with lower rankings in the general marketisation index: China's poorer provinces, including Qinghai and Guizhou, in the west and south-west of the country.

One reason for this inconsistency could be that provinces with low marketisation are followers of the price set by the central government. That is, local governments cannot influence prices according to local conditions or interests. Provinces with a higher degree of marketisation, however, are typically more developed, and this comes with greater rights to intervene in - or to allow markets to decidelocal energy markets.

Further research is required to provide more detailed explanations of the different levels of marketisation of different energy categories in different provinces in China. One suggestion would be to calculate a marketisation index, as proposed in this study, for single durable goods, non-durable goods and services across China. Only with this type of panel data study that captures market price integration across regions, time and products in China will it be possible to better understand the marketisation process in China.

Finally, the study focuses on internal integration and does not discuss the impact of international integration of energy markets. With reform and opening one would expect price movements to be influenced by international price movements. The global price of coal, gas and oil varied enormously over the period of the study (see Figures 2.3 and 2.4 in Chapter 2 of this volume) and so could be expected to influence domestic movements of energy prices. This too would be an avenue for future research.

\section{References}

Akhmedjonov, A., Chi Keung Lau, M. and İzgi, B.B. (2013), New evidence of regional income divergence in post-reform Russia, Applied Economics, 45(18): 2675-82.

Bachmeier, L.J. and Griffin, J.M. (2006), Testing for market integration: Crude oil, coal, and natural gas, The Energy Journal, 27: 55-71.

Berkowitz, J. and Kilian, L. (2000), Recent developments in bootstrapping time series, Econometric Reviews, 19(1): 1-48.

Bilgin, M.H., Lau, C.K.M., Demir, E. and Astrauskienè, N. (2010), Rental price convergence in a developing economy: New evidence from nonlinear panel unit root test, International Journal of Strategic Property Management, 14(3): 245-57. 
Breuer, J.B., McNown, R. and Wallace, M. (2002), Series-specific unit root tests with panel data, Oxford Bulletin of Economics and Statistics, 64(5): 527-46.

Chen, M. (2014), The development of Chinese gas pricing, OIES Paper NG 89, Oxford: Oxford Institute for Energy Studies.

Energy Information Administration (EIA) (2012), China Country Analysis Brief. Energy Information Administration. www.eia.doe.gov. Retrieved October 2012.

Evans, P. (1998), Using Panel Data to Evaluate Growth Theories, International Economic Review, 39: 295-306.

Fan, C.S. and Wei, X. (2006), The law of one price: Evidence from the transitional economy of China, The Review of Economics and Statistics, 88(4): 682-97.

Fan, G., Wang, X. and Zhu, H. (2011), NERI index of marketisation of China's provinces 2011, Beijing: Economic Science Publishing House.

Heffer, P. and Olegario, A. (2010), Fertilizer subsidy situation in selected countries: 2008/09, Paris: International Fertiliser Industry Association. Available from: www.fertilizer.org.

Kapetanios, G., Shin, Y. and Snell, A. (2003), Testing for a unit root in the nonlinear STAR framework, Journal of Econometrics, 112(2): 359-79.

Lan, Y. and Sylwester, K. (2010), Does the law of one price hold in China? Testing price convergence using disaggregated data, China Economic Review, 21(2): 224-36.

Lau, C.K.M. (2010), New evidence about regional income divergence in China, China Economic Review, 21(2): 293-309.

Lau, C.K.M., Demir, E. and Bilgin, M.H. (2015), A nonlinear model of military expenditure convergence: Evidence from Estar nonlinear unit root test, Defence and Peace Economics: 1-12.

Lau, C.K.M., Fung, K.W.T. and Pugalis, L. (2014), Is health care expenditure across Europe converging? Findings from the application of a nonlinear panel unit root test, Eurasian Business Review, 4(2): 137-56.

Lau, M.C.K., Suvankulov, F. and Ogucu, F. (2012), Price regulation and relative price convergence: Evidence from the retail gasoline market in Canada, Energy Policy, 40: 325-34.

Ma, H., Oxley, L. and Gibson, J. (2009), Gradual reforms and the emergence of energy market in China: Evidence from tests for convergence of energy prices, Energy Policy, 37(11): 4834-50. 
Ma, H., Oxley, L. and Gibson, J. (2010), China's energy economy: A survey of the literature, Economic Systems, 34(2): 105-32.

National Bureau of Statistics (NBS) (2007), China Energy Statistical Yearbook 2007, Beijing: China Statistics Press.

Parsley, D. and Wei, S.J. (1996), Convergence to the law of one price without trade barriers or currency fluctuations, Quarterly Journal of Economics, 111(4): 1211-36.

Suvankulov, F., Lau, M.C.K. and Ogucu, F. (2012), Price regulation and relative price convergence: Evidence from the retail gasoline market in Canada, Energy Policy, 40: 325-34.

Taylor, A.M. (2001), Potential pitfalls for the purchasing-power-parity puzzle? Sampling and specification biases in mean-reversion tests of the law of one price, Econometrica, 69(2): 473-98.

United Nations Conference on Trade and Development (UNCTAD) (2012), Special challenges facing emerging market and least developed countries owing to the volatility in commodity prices, Geneva: UNCTAD. Available from: dgff.unctad.org/chapter3/3.5.html. Retrieved 6 April 2013.

United States Environmental Protection Agency (US EPA) (2012), China's energy markets: Anhui, Chongqing, Henan, Inner Mongolia, and Guizhou Provinces, December, Washington, DC: US EPA. Available from: epa.gov/cmop/ docs/2012ChinaEnergyMarket.pdf.

Wu, J.L. and Lee, H.Y. (2009), A revisit to the non-linear mean reversion of real exchange rates: Evidence from a series-specific non-linear panel unit-root test, Journal of Macroeconomics, 31(4): 591-601.

$\mathrm{Xu}, \mathrm{C}$. (2011), The fundamental institutions of China's reforms and development, Journal of Economic Literature, 49(4): 1076-151.

Young, A. (2000), The razor's edge: Distortions and incremental reform in the People's Republic of China, The Quarterly Journal of Economics, 115(4): 1091-135.

Zhou, N., Levine, M.D. and Price, L. (2010), Overview of current energyefficiency policies in China, Energy Policy, 38(11): 6439-52. doi: dx.doi. org/10.1016/j.enpol.2009.08.015. 


\section{Appendix}

Table A6.1 Detailed description of dataset by product

\begin{tabular}{|c|c|}
\hline Product & Regions in original dataset \\
\hline Natural gas manufacture & $\begin{array}{l}28 \text { cities: } \\
\text { Beijing, Chengdu, Harbin, Haikou, Hangzhou, Hefei, Hohhot, Jinan, } \\
\text { Lanzhou, Nanjing, Nanning, Ningbo, Oingdao, Xiamen, Shanghai, } \\
\text { Shenyang, Shijiazhuang, Taiyuan, Tianjin, Urumqi, Wuhan, Xi'an, Xining, } \\
\text { Yinchuan, Changchun, Changsha, Zhengzhou, Chongqing }\end{array}$ \\
\hline Natural gas_service & $\begin{array}{l}28 \text { cities: } \\
\text { Beijing, Chengdu, Harbin, Haikou, Hangzhou, Hefei, Hohhot, Jinan, } \\
\text { Lanzhou, Nanjing, Nanning, Ningbo, Qingdao, Xiamen, Shanghai, } \\
\text { Shenyang, Shijiazhuang, Taiyuan, Tianjin, Urumqi, Wuhan, Xi'an, Xining, } \\
\text { Yinchuan, Changchun, Changsha, Zhengzhou, Chongqing }\end{array}$ \\
\hline Gas_cokeoven & $\begin{array}{l}22 \text { cities: } \\
\text { Dalian, Guiyang, Harbin, Hangzhou, Hohhot, Jinan, Kunming, } \\
\text { Nanchang, Nanjing, Ningbo, Qingdao, Shanghai, Shenyang, } \\
\text { Shijiazhuang, Taiyuan, Tianjin, Wuhan, Xi'an, Yinchuan, Changchun, } \\
\text { Changsha, Zhengzhou }\end{array}$ \\
\hline Electricity_manufacture_35k+ & $\begin{array}{l}36 \text { cities: } \\
\text { Beijing, Chengdu, Dalian, Fuzhou, Guangzhou, Guiyang, Harbin, } \\
\text { Haikou, Hangzhou, Hefei, Hohhot, Jinan, Kunming, Lhasa, Lanzhou, } \\
\text { Nanchang, Nanjing, Nanning, Ningbo, Qingdao, Xiamen, Shanghai, } \\
\text { Shenzhen, Shenyang, Shijiazhuang, Taiyuan, Tianjin, Urumqi, } \\
\text { Wuhan, Xi'an, Xining, Yinchuan, Changchun, Changsha, Zhengzhou, } \\
\text { Chongqing }\end{array}$ \\
\hline Gasoline90\# & $\begin{array}{l}60 \text { cities: } \\
\text { Baotou, Baoji, Beijing, Chengdu, Dalian, Daqing, Datong, Fuzhou, } \\
\text { Ganzhou, Golmud, Guangzhou, Guiyang, Harbin, Haikou, Hangzhou, } \\
\text { Hefei, Hengyang, Hohhot, Jilin, Jinan, Jiaxing, Jiangmen, Jingmen, } \\
\text { Kunming, Lhasa, Lanzhou, Liuzhou, Nanchang, Nanjing, Nanning, } \\
\text { Ningbo, Qingdao, Qujing, Quanzhou, Sanya, Xiamen, Shanghai, } \\
\text { Shenzhen, Shenyang, Shijiazhuang, Taiyuan, Tianjin, Tongling, Urumqi, } \\
\text { Wuzhong, Wuhan, Xi'an, Xining, Xingtai, Xuzhou, Yantai, Yili, Yinchuan, } \\
\text { Changchun, Changsha, Zhengzhou, Chongqing, Zhoukou, Zigong, Zunyi }\end{array}$ \\
\hline Gasoline93\# & $\begin{array}{l}60 \text { cities: } \\
\text { Baotou, Baoji, Beijing, Chengdu, Dalian, Daqing, Datong, Fuzhou, } \\
\text { Ganzhou, Golmud, Guangzhou, Guiyang, Harbin, Haikou, Hangzhou, } \\
\text { Hefei, Hengyang, Hohhot, Jilin, Jinan, Jiaxing, Jiangmen, Jingmen, } \\
\text { Kunming, Lhasa, Lanzhou, Liuzhou, Nanchang, Nanjing, Nanning, } \\
\text { Ningbo, Qingdao, Qujing, Quanzhou, Sanya, Xiamen, Shanghai, } \\
\text { Shenzhen, Shenyang, Shijiazhuang, Taiyuan, Tianjin, Tongling, Urumqi, } \\
\text { Wuzhong, Wuhan, Xi'an, Xining, Xingtai, Xuzhou, Yantai, Yili, Yinchuan, } \\
\text { Changchun, Changsha, Zhengzhou, Chongqing, Zhoukou, Zigong, Zunyi }\end{array}$ \\
\hline Gasoline97\# & $\begin{array}{l}59 \text { cities: } \\
\text { Baotou, Baoji, Beijing, Chengdu, Dalian, Daqing, Datong, Fuzhou, } \\
\text { Ganzhou, Golmud, Guangzhou, Guiyang, Harbin, Haikou, Hangzhou, } \\
\text { Hefei, Hengyang, Hohhot, Jilin, Jinan, Jiaxing, Jiangmen, Jingmen, } \\
\text { Kunming, Lanzhou, Liuzhou, Nanchang, Nanjing, Nanning, Ningbo, } \\
\text { Qingdao, Qujing, Quanzhou, Sanya, Xiamen, Shanghai, Shenzhen, } \\
\text { Shenyang, Shijiazhuang, Taiyuan, Tianjin, Tongling, Urumqi, Wuzhong, } \\
\text { Wuhan, Xi'an, Xining, Xingtai, Xuzhou, Yantai, Yili, Yinchuan, Changchun, } \\
\text { Changsha, Zhengzhou, Chongqing, Zhoukou, Zigong, Zunyi }\end{array}$ \\
\hline
\end{tabular}




\begin{tabular}{|c|c|}
\hline Product & Regions in original dataset \\
\hline Diesel_0\# & $\begin{array}{l}60 \text { cities: } \\
\text { Baotou, Baoji, Beijing, Chengdu, Dalian, Daqing, Datong, Fuzhou, } \\
\text { Ganzhou, Golmud, Guangzhou, Guiyang, Harbin, Haikou, Hangzhou, } \\
\text { Hefei, Hengyang, Hohhot, Jilin, Jinan, Jiaxing, Jiangmen, Jingmen, } \\
\text { Kunming, Lhasa, Lanzhou, Liuzhou, Nanchang, Nanjing, Nanning, } \\
\text { Ningbo, Qingdao, Qujing, Quanzhou, Sanya, Xiamen, Shanghai, } \\
\text { Shenzhen, Shenyang, Shijiazhuang, Taiyuan, Tianjin, Tongling, Urumqi, } \\
\text { Wuzhong, Wuhan, Xian, Xining, Xingtai, Xuzhou, Yantai, Yili, Yinchuan, } \\
\text { Changchun, Changsha, Zhengzhou, Chongqing, Zhoukou, Zigong, Zunyi }\end{array}$ \\
\hline Diesel_10\# & $\begin{array}{l}41 \text { cities: } \\
\text { Baotou, Baoji, Beijing, Dalian, Daqing, Datong, Ganzhou, Golmud, } \\
\text { Guiyang, Harbin, Hangzhou, Hefei, Hohhot, Jilin, Jinan, Jingmen, } \\
\text { Jiaxing, Lhasa, Lanzhou, Liuzhou, Ningbo, Qingdao, Shanghai, } \\
\text { Shenyang, Shijiazhuang, Taiyuan, Tianjin, Tongling, Urumqi, Wuzhong, } \\
\text { Xi'an, Xining, Xingtai, Xuzhou, Yantai, Yili, Yinchuan, Changchun, } \\
\text { Zhengzhou, Zhoukou, Zunyi }\end{array}$ \\
\hline Coal_mixed4500-5000 & $\begin{array}{l}8 \text { provinces: } \\
\text { Guizhou, Hebei, Henan, Heilongjiang, Inner Mongolia, Shandong, } \\
\text { Shanxi, Sichuan }\end{array}$ \\
\hline Coal_mixed5000-5500 & $\begin{array}{l}7 \text { provinces: } \\
\text { Guizhou, Henan, Heilongjiang, Inner Mongolia, Shandong, Shanxi, } \\
\text { Shaanxi }\end{array}$ \\
\hline Coal_mixed5500-6000 & $\begin{array}{l}6 \text { provinces: } \\
\text { Guizhou, Henan, Heilongjiang, Inner Mongolia, Shandong, Shanxi }\end{array}$ \\
\hline Coal_mixed6000+ & $\begin{array}{l}5 \text { provinces: } \\
\text { Guizhou, Heilongjiang, Inner Mongolia, Shandong, Shaanxi }\end{array}$ \\
\hline Coal_metallurgical_1st & $\begin{array}{l}5 \text { provinces: } \\
\text { Guizhou, Hebei, Inner Mongolia, Shandong, Shanxi }\end{array}$ \\
\hline Coal_plant_8th & $\begin{array}{l}4 \text { provinces: } \\
\text { Guizhou, Hebei, Inner Mongolia, Shandong }\end{array}$ \\
\hline Coal_plant_9th & $\begin{array}{l}3 \text { provinces: } \\
\text { Guizhou, Inner Mongolia, Shandong }\end{array}$ \\
\hline Coal_plant_10th & $\begin{array}{l}7 \text { provinces: } \\
\text { Guizhou, Henan, Heilongjiang, Inner Mongolia, Shandong, Shanxi, } \\
\text { Sichuan }\end{array}$ \\
\hline Coal_fertiliser & $\begin{array}{l}2 \text { provinces: } \\
\text { Guizhou, Shandong }\end{array}$ \\
\hline Coal_cement & $\begin{array}{l}3 \text { provinces: } \\
\text { Anhui, Guizhou, Inner Mongolia, Shandong }\end{array}$ \\
\hline Coal_other & $\begin{array}{l}4 \text { provinces: } \\
\text { Guizhou, Inner Mongolia, Shandong, Sichuan }\end{array}$ \\
\hline
\end{tabular}


This text is taken from China's Domestic Transformation in a Global Context, edited by Ligang Song, Ross Garnaut, Cai Fang \& Lauren Johnston, published 2015 by ANU Press, The Australian National University, Canberra, Australia. 